Check for updates

Cite this: Chem. Sci., 2017, 8, 5385

Received 22nd April 2017

Accepted 9th May 2017

DOI: $10.1039 / \mathrm{c} 7 \mathrm{sc} 01797 \mathrm{a}$

rsc.li/chemical-science

\section{Criegee intermediate-hydrogen sulfide chemistry at the air/water interface $\uparrow$}

\begin{abstract}
Manoj Kumar, $\star^{a}$ Jie Zhong, $\xi^{a}$ Joseph S. Francisco*a and Xiao C. Zeng*ab
We carry out Born-Oppenheimer molecular dynamic simulations to show that the reaction between the smallest Criegee intermediate, $\mathrm{CH}_{2} \mathrm{OO}$, and hydrogen sulfide $\left(\mathrm{H}_{2} \mathrm{~S}\right)$ at the air/water interface can be observed within few picoseconds. The reaction follows both concerted and stepwise mechanisms with former being the dominant reaction pathway. The concerted reaction proceeds with or without the involvement of one or two nearby water molecules. An important implication of the simulation results is that the Criegee- $\mathrm{H}_{2} \mathrm{~S}$ reaction can provide a novel non-photochemical pathway for the formation of a $\mathrm{C}-\mathrm{S}$ linkage in clouds and could be a new oxidation pathway for $\mathrm{H}_{2} \mathrm{~S}$ in terrestrial, geothermal and volcanic regions.
\end{abstract}

Carbon-sulfur linkages are ubiquitous in atmospheric, combustion, and biological chemistries. Thioaldehydes comprise an important class of carbon-sulfur compounds that has a broad chemical appeal. For example, thioformaldehyde (HCHS) has been detected in dark clouds, the interstellar clouds ${ }^{1}$ and circumstellar envelope around an asymptotic giant branch star. ${ }^{2}$ HCHS is also believed to play a key role in the photochemical evolution of sulfurcontaining species in the Earth's atmosphere and other astronomical systems. ${ }^{1 c, 2}$ In synthetic organic chemistry, thioaldehydes are used as key building blocks. ${ }^{3}$ The high intrinsic reactivity and polarisability of thioformyl group makes possible the construction of new carbon bonds with remarkable selectivity. ${ }^{4}$ Thioaldehydes also possess potential biological activities. ${ }^{5}$ Recently, thioaldehydes have been implicated as common intermediates in biosynthetic pathways in methanogens. ${ }^{6,7}$ Despite their broad profile, the laboratory synthesis of simpler aliphatic thioaldehydes has been a great challenge because of their tendency towards oligomerization. ${ }^{8}$

In the atmosphere, thioaldehydes are believed to be formed by the nucleophilic attack of $\mathrm{SH}^{-}$ion on the carbonyl group. However, it has recently been suggested that the gas-phase reaction between Criegee intermediate or a carbonyl compound and

\footnotetext{
${ }^{a}$ Department of Chemistry, University of Nebraska-Lincoln, Lincoln, Nebraska, 68588, USA. E-mail: xzeng1@unl.edu; jfrancisco3@unl.edu

${ }^{b}$ Beijing Advanced Innovation Center for Soft Matter Science and Engineering, Beijing University of Chemical Technology, Beijing 100029, China

$\dagger$ Electronic supplementary information (ESI) available: Radial distribution functions for the $\mathrm{H}_{2} \mathrm{~S}-\mathrm{H}_{2} \mathrm{O}$ and $\mathrm{CH}_{2} \mathrm{OO}-\mathrm{H}_{2} \mathrm{O}$ interactions; probability distributions $P\left(\theta_{1}, \theta_{2}\right)$ for $\mathrm{H}_{2} \mathrm{~S}$ at the air-water interface; videos of trajectories of the BOMD simulations for the concerted and stepwise reactions between $\mathrm{CH}_{2} \mathrm{OO}$ and $\mathrm{H}_{2} \mathrm{~S}$ at the air/water interface; BLYP/aug-cc-pVTZ-optimized geometries of key stationary points for the gas-phase reactions of $\mathrm{CH}_{2} \mathrm{OO}$ with $\mathrm{H}_{2} \mathrm{~S}$ and $\mathrm{H}_{2} \mathrm{~S}-\mathrm{H}_{2} \mathrm{O}$, respectively. See DOI: $10.1039 / \mathrm{c} 7 \mathrm{sc} 01797 \mathrm{a}$

\$ These authors contributed equally.
}

hydrogen sulfide $\left(\mathrm{H}_{2} \mathrm{~S}\right)$ under water or acid catalysis could account for the atmospheric formation of thioaldehydes and provide useful guidelines for efficiently synthesizing thioaldehydes within laboratory environment. ${ }^{79}$ Criegee intermediates are formed in the cycloaddition reactions between ozone and olefins. ${ }^{10}$ Ever since Criegee intermediates have directly been detected in the gas phase, ${ }^{11}$ understanding their chemistry using experimental and theoretical means has become an important avenue of atmospheric research. ${ }^{12}$ Criegee intermediates are not only important in atmospheric context, but also play a key role in enzymatic reactions, ${ }^{13}$ pharmaceutical pathways and general synthetic organic reactions. ${ }^{14} \mathrm{H}_{2} \mathrm{~S}$ is released into the air naturally and as a result of human activity. Natural sources, such as swamps, bogs, natural gases, geothermal hot springs, fumaroles and volcanoes, account for about $90 \%$ of the total amount of $\mathrm{H}_{2} \mathrm{~S}$ in the atmosphere. ${ }^{15}$ Typical $\mathrm{H}_{2} \mathrm{~S}$ concentrations in volcanic and geothermal regions are about 500 parts per billion. ${ }^{16}$ However, gypsum drywells present in the construction and demolition wastes could produce significant amounts of $\mathrm{H}_{2} \mathrm{~S}$ ranging from 7 parts per million (ppm) to $100 \mathrm{ppm}^{17}$ In certain cases, more dangerous levels of 5000 $12000 \mathrm{ppm}$ were also measured..$^{18} \mathrm{H}_{2} \mathrm{~S}$ is also emitted by plants. ${ }^{19}$ Estimates of the terrestrial emission rates of $\mathrm{H}_{2} \mathrm{~S}$ range from 58 to 110 million tons of sulfur per year. ${ }^{20}$ There is significant literature suggesting that in the forested environments, ${ }^{21}$ the Criegee intermediates could be formed from the interaction of terpenes with ozone. Clearly, the thioaldehyde-forming Criegee- $\mathrm{H}_{2} \mathrm{~S}$ chemistry could be locally important in the troposphere.

Aerosols, fog and clouds are believed to play a key role in atmospheric chemistry. ${ }^{22}$ In the atmosphere, the abundance of aerosols can rise up to $\sim 10^{8}$ to $10^{9} \mathrm{~m}^{-3}$, and the maximum surface area of the aerosols in clouds can be $\sim 10^{-9} \mathrm{~m}^{2} .^{23}$ This suggests that the air/water interface, which is characteristic of the surface of oceans, lakes, and atmospheric aerosols, may also play a more direct role in the Criegee reactions due to their 
ability to concentrate and align reacting species in a water restricting environment. However, most of the Criegee reactions have only been examined in the gas phase until recently ${ }^{22 b}$ when the dynamics of the Criegee-water $\left(\mathrm{H}_{2} \mathrm{O}\right)$ reaction at the air/ water interface was investigated in detail using the adaptive buffered force Quantum Mechanics/Molecular Mechanics dynamics simulations (adbf-QM/MM). Contrary to the previously established concerted mechanism in the gas-phase, a significant fraction of the Criegee- $\mathrm{H}_{2} \mathrm{O}$ reaction at the air/ water interface follows a stepwise mechanism.

In the atmosphere, the major sink of $\mathrm{H}_{2} \mathrm{~S}$ is assumed to be its reaction with the $\mathrm{OH}$ radical. However, nearly half of $\mathrm{H}_{2} \mathrm{~S}$ emitted into the troposphere comes from ocean, ${ }^{24}$ suggesting that the aqueous surface chemistry of $\mathrm{H}_{2} \mathrm{~S}$ could play an important role in its tropospheric oxidation under certain conditions. In this article, we show a direct evidence, based on the Born-Oppenheimer molecular dynamics (BOMD) simulations, that the reaction between the simplest Criegee intermediate, $\mathrm{CH}_{2} \mathrm{OO}$, and $\mathrm{H}_{2} \mathrm{~S}$ at the air/water interface occurs within few picoseconds and results in the formation of thioaldehyde. In the terrestrial regions, the Criegee intermediate and $\mathrm{H}_{2} \mathrm{~S}$ may first react in the gas-phase to form the Criegee- $\mathrm{H}_{2} \mathrm{~S}$ complex, which then could get adsorbed on the water droplet and allow the subsequent reaction. The reaction at the air-water interface follows both concerted and stepwise mechanisms. To our knowledge, this is the first evidence that suggests the role of the water droplets (e.g., clouds) in catalysing the non-photochemical formation of a $\mathrm{C}-\mathrm{S}$ linkage. These results not only reveal a general effect of the water droplet on the Criegee$\mathrm{H}_{2} \mathrm{~S}$ chemistry, but also offer valuable insights into the tropospheric oxidation of $\mathrm{H}_{2} \mathrm{~S}$ on the aqueous surface.

\section{Methods}

The BOMD simulations were performed on the basis of density functional theory (DFT) method implemented in the $\mathrm{CP} 2 \mathrm{~K}^{\mathbf{2 5}}$ code. The reaction between $\mathrm{CH}_{2} \mathrm{OO}$ and $\mathrm{H}_{2} \mathrm{~S}$ at the air/water interface is investigated using a model system that contained $191 \mathrm{H}_{2} \mathrm{O}$ molecules, one $\mathrm{CH}_{2} \mathrm{OO}$ molecule, and one $\mathrm{H}_{2} \mathrm{~S}$ molecule, as shown in Fig. 1. The solvation structure of $\mathrm{H}_{2} \mathrm{~S}$ and $\mathrm{CH}_{2} \mathrm{OO}$ adsorbed on the water droplet was also examined. The radius of the water droplet in our system is about $11 \AA$. The dimensions of the simulation box are $x=35 \AA, y=35 \AA$, and $z=$ $35 \AA$. This translates into the smallest distance of about $14 \AA$ between the adjacent periodic images of the water droplet. Apparently, the size of the box is large enough to neglect any interactions between the adjacent periodic images of the water droplet. Prior to the BOMD simulations, the system was fully relaxed using a DFT method, in which the exchange and correlation interaction is treated with the Becke-Lee-Yang-Parr $(B L Y P)^{26}$ functional. The Grimme's dispersion correction method $^{27}$ is applied to account for the weak dispersion interactions. A double- $\zeta$ Gaussian basis set combined with an auxiliary basis $\operatorname{set}^{28}$ and the Goedecker-Teter-Hutter (GTH) norm-conserved pseudopotentials ${ }^{29}$ are adopted to treat the valence and the core electrons, respectively. An energy cutoff of 280 Rydberg is set for the plane wave basis set and 40 Rydberg for the Gaussian basis set. The BOMD simulations were carried

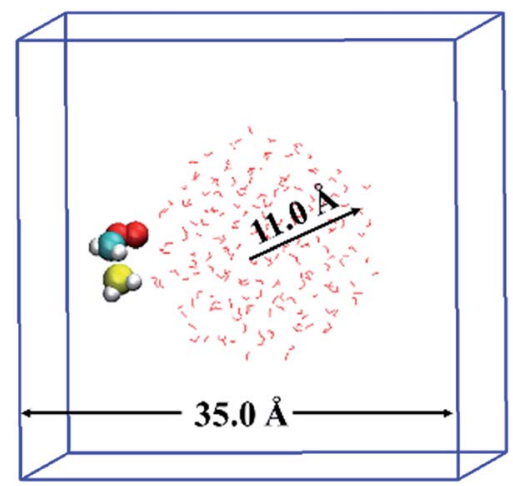

Fig. 1 Initial configuration of Criegee intermediate, $\mathrm{CH}_{2} \mathrm{OO}$ and hydrogen sulphide, $\mathrm{H}_{2} \mathrm{~S}$ adsorbed on the water droplet of 191 water molecules. The white, red, cyan and yellow colours represent $\mathrm{H}, \mathrm{O}, \mathrm{C}$ and $\mathrm{S}$ atoms, respectively. $\mathrm{CH}_{2} \mathrm{OO}$ and $\mathrm{H}_{2} \mathrm{~S}$ are shown in ball-stick representation whereas the water droplet is shown in line representation.

out in the constant volume and temperature ensemble, with the Nose-Hoover chain method for controlling the temperature (300 K) of the system. The integration step is set as $1 \mathrm{fs}$, which has been previously shown to achieve sufficient energy conservation for the water system. ${ }^{22 \boldsymbol{b}-\boldsymbol{d}}$

In addition, the gas-phase reaction of $\mathrm{CH}_{2} \mathrm{OO}$ with $\mathrm{H}_{2} \mathrm{~S}$ and $\mathrm{H}_{2} \mathrm{~S}-\mathrm{H}_{2} \mathrm{O}$ complex was examined. The geometries of all the stationary points on the potential energy surfaces for both reactions were fully optimized using the $\mathrm{BLYP}^{26}$ functional, and aug-cc-pVTZ ${ }^{30}$ basis set. The harmonic vibrational frequency analyses were performed to ascertain the identity of the stable minima and transition states, as well as for estimating the zeropoint electronic energy corrections for the reactants, products, transition states, and intermediates. The single point calculations using the coupled cluster single and double substitution method with a perturbative treatment of triple excitations $[\operatorname{CCSD}(\mathrm{T})]^{31}$ and the aug-cc-pVTZ basis set were performed on the BLYP optimized geometries to further improve the energetics. These DFT and $\operatorname{CCSD}(\mathrm{T})$ calculations were carried out using Gaussian $09^{32}$ software.

\section{Results and discussion}

\section{Gas-phase reaction}

First, the gas-phase reaction between $\mathrm{CH}_{2} \mathrm{OO}$ and $\mathrm{H}_{2} \mathrm{~S}$ with or without one $\mathrm{H}_{2} \mathrm{O}$ molecule is examined at the $\operatorname{CCSD}(\mathrm{T}) /$ aug-ccpVTZ//BLYP/aug-cc-pVTZ level of theory. Although the Criegee intermediate entails appreciable multiconfigurational character, ${ }^{33}$ especially when the substituents on the Criegee moiety are electron-withdrawing groups, ${ }^{34}$ previous theoretical studies ${ }^{34-37}$ have shown that the coupled-cluster//DFT level of theory can provide reasonable description of its unimolecular and bimolecular chemistry due in part to relatively small fraction $(<15 \%)$ of the total wave-function that accounts for multi-reference nature of Criegee intermediate. The computed reaction profiles for the gasphase $\mathrm{CH}_{2} \mathrm{OO}+\mathrm{H}_{2} \mathrm{~S}$ and $\mathrm{CH}_{2} \mathrm{OO}+\mathrm{H}_{2} \mathrm{~S} \cdots \mathrm{H}_{2} \mathrm{O}$ reactions are shown in Fig. 2. The uncatalyzed addition of $\mathrm{H}_{2} \mathrm{~S}$ across the -COO moiety 


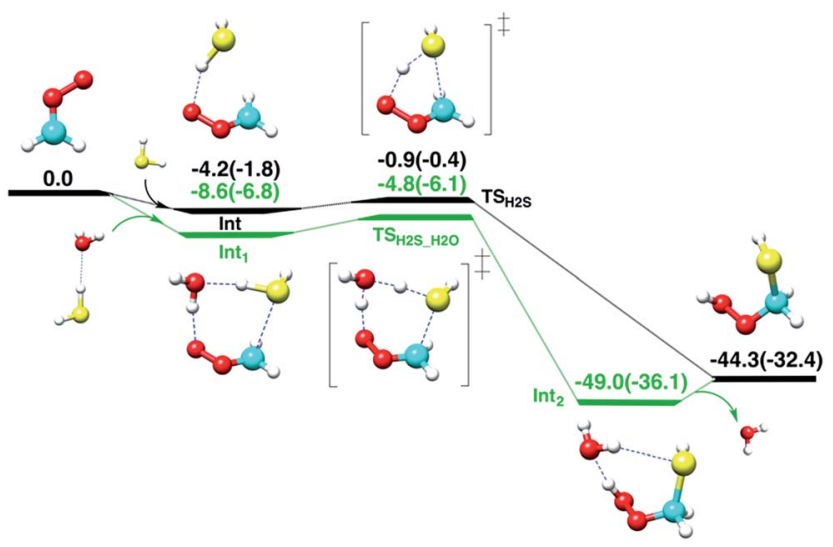

Fig. 2 The CCSD(T)/aug-cc-pVTZ//BLYP/aug-cc-pVTZ computed reaction profiles in units of $\mathrm{kcal} \mathrm{mol}^{-1}$ (at $298.15 \mathrm{~K}, 1 \mathrm{~atm}$ ) for the reactions of $\mathrm{CH}_{2} \mathrm{OO}$ with hydrogen sulfide and hydrogen sulfidewater complex. The white, red, gray and yellow spheres represent $\mathrm{H}$, $\mathrm{O}, \mathrm{C}$ and S atoms, respectively. The BLYP/aug-cc-pVTZ calculated values are given in parentheses.

of $\mathrm{CH}_{2} \mathrm{OO}$ occurs in a concerted manner, which leads to the exothermic formation of ( $\mathrm{HS}) \mathrm{CH}_{2}(\mathrm{OOH})$. The computed barrier for the uncatalyzed reaction, with respect to the $\mathrm{CH}_{2} \mathrm{OO} \cdots \mathrm{H}_{2} \mathrm{~S}$ complex, is $3.3 \mathrm{kcal} \mathrm{mol}^{-1}$ at the $\operatorname{CCSD}(\mathrm{T}) /$ aug-cc-pVTZ//BLYP/augcc-pVTZ level. This barrier is $1.9 \mathrm{kcal} \mathrm{mol}^{-1}$ larger than that calculated at the BLYP/aug-cc-pVTZ level. The $\operatorname{CCSD(T)/aug-cc-~}$ pVTZ//BLYP/aug-cc-pVTZ calculated exothermicity of the reaction is $44.3 \mathrm{kcal} \mathrm{mol}^{-1}, 11.9 \mathrm{kcal} \mathrm{mol}^{-1}$ larger than that calculated with BLYP/aug-cc-pVTZ method. These comparisons suggest that the electron correlation appreciably impacts the reaction barrier and energetics, and must be accounted for. For the concerted $\mathrm{CH}_{2} \mathrm{OO}+$ $\mathrm{H}_{2} \mathrm{~S} \cdots \mathrm{H}_{2} \mathrm{O}$ reaction, the transition state is submerged below free reactants, and the product complex ( $\mathrm{HS}) \mathrm{CH}_{2}(\mathrm{OOH}) \cdots \mathrm{H}_{2} \mathrm{O}$ is 4.7 kcal mol ${ }^{-1}$ more stable than separated (HS) $\mathrm{CH}_{2}(\mathrm{OOH})$ and $\mathrm{H}_{2} \mathrm{O}$ at the $\operatorname{CCSD}(\mathrm{T}) /$ aug-cc-pVTZ//BLYP/aug-cc-pVTZ level. Notably, the calculated barrier for the $\mathrm{CH}_{2} \mathrm{OO}+\mathrm{H}_{2} \mathrm{~S} \cdots \mathrm{H}_{2} \mathrm{O}$ reaction relative to the $\mathrm{Int}_{1}$, is $3.8 \mathrm{kcal} \mathrm{mol}^{-1}, 0.5 \mathrm{kcal} \mathrm{mol}^{-1}$ larger than that for the uncatalyzed reaction.

\section{Air/water interface reaction}

There is literature precedence suggesting that aerosols, fog and cloud water may play a key role in the atmospheric chemistry. ${ }^{22}$ Here, we provide the BOMD simulation evidence of a reaction between the Criegee intermediate, $\mathrm{CH}_{2} \mathrm{OO}$, and $\mathrm{H}_{2} \mathrm{~S}$ on the air/ water surface. Unlike in the gas phase, the $\mathrm{CH}_{2} \mathrm{OO} \cdots \mathrm{H}_{2} \mathrm{~S}$ reaction at the air/water interface can be observed directly in the BOMD simulation trajectory after a few ps, and the reaction follows both concerted and stepwise mechanisms. We have performed total 16 BOMD simulations to study the $\mathrm{CH}_{2} \mathrm{OO} \cdots \mathrm{H}_{2} \mathrm{~S}$ reaction on the water droplet, one BOMD simulation to study the dynamic behaviour of $\mathrm{CH}_{2} \mathrm{OO}$ on the water droplet, and one BOMD simulation to study the dynamic behaviour of $\mathrm{H}_{2} \mathrm{~S}$ on the water droplet. In 8 of the 16 simulations, the reaction between $\mathrm{CH}_{2} \mathrm{OO}$ and $\mathrm{H}_{2} \mathrm{O}$ molecules has been observed whereas in another 8 simulations, the
$\mathrm{CH}_{2} \mathrm{OO} \cdots \mathrm{H}_{2} \mathrm{~S}$ reaction occurs. It is important to note that the $\mathrm{CH}_{2} \mathrm{OO} \cdots \mathrm{H}_{2} \mathrm{~S}$ reaction on the water droplet is only observed when $\mathrm{CH}_{2} \mathrm{OO}$ and $\mathrm{H}_{2} \mathrm{~S}$ are placed no farther than $4.0 \AA$ A. Since the $\mathrm{CH}_{2} \mathrm{OO} \cdots \mathrm{H}_{2} \mathrm{O}$ reaction at the air/water interface has been described in detail elsewhere, ${ }^{22 b}$ here, we mainly focus on the $\mathrm{CH}_{2} \mathrm{OO} \cdots \mathrm{H}_{2} \mathrm{~S}$ reaction. The most dominant mechanistic pathway for the $\mathrm{CH}_{2} \mathrm{OO} \cdots \mathrm{H}_{2} \mathrm{~S}$ reaction involves the single water molecule-mediated concerted reaction, which accounts for $50 \%$ of the total number of $\mathrm{CH}_{2} \mathrm{OO} \cdots \mathrm{H}_{2} \mathrm{~S}$ reactions on the water droplet. A significant fraction (25\%) of the $\mathrm{CH}_{2} \mathrm{OO} \cdots \mathrm{H}_{2} \mathrm{~S}$ reactions involve the concerted reaction mediated by two $\mathrm{H}_{2} \mathrm{O}$ molecules. All the possible reaction pathways for the $\mathrm{CH}_{2} \mathrm{OO} \cdots$ $\mathrm{H}_{2} \mathrm{~S}$ reaction on the water droplet are described in detail below:

\section{Concerted reaction at the air/water interface}

Most of the $\mathrm{CH}_{2} \mathrm{OO} \cdots \mathrm{H}_{2} \mathrm{~S}$ reaction (87.5\%) occurs concertedly. There are three different concerted pathways that have been observed in the BOMD simulations: (i) the direct reaction between $\mathrm{CH}_{2} \mathrm{OO}$ and $\mathrm{H}_{2} \mathrm{~S}(12.5 \%)$, (ii) one $\mathrm{H}_{2} \mathrm{O}$ moleculemediated reaction (50\%), and (iii) two $\mathrm{H}_{2} \mathrm{O}$ moleculesmediated reaction (25\%). The mechanistic details of the concerted direct reaction are quite similar to that of the uncatalyzed reaction in the gas phase. As shown in Fig. 3, the formation of a prereaction complex between $\mathrm{CH}_{2} \mathrm{OO}$ and $\mathrm{H}_{2} \mathrm{~S}$ is observed at $\sim 5.33$ ps, where the $\mathrm{C}-\mathrm{S}$ bond is $3.1 \AA$ long, and there is virtually no interaction between the terminal Criegee oxygen and thiol proton $\left(\mathrm{S}-\mathrm{H}_{1}\right)$. At $\sim 5.35 \mathrm{ps}$, the $\mathrm{CH}_{2} \mathrm{OO} \cdots \mathrm{H}_{2} \mathrm{~S}$ complex looks more like the transition state in the gas phase, where the $\mathrm{C}-\mathrm{S}$ bond is shortened to $1.9 \AA$ while the $\mathrm{S}-\mathrm{H}_{1}$ bond is elongated to $1.8 \AA$. There is also a $1.6 \AA$ bond between the terminal Criegee oxygen and thiol proton $\left(\mathrm{O}_{1}-\mathrm{H}_{1}\right)$. This complex converts into the final product, (HS) $\mathrm{CH}_{2}(\mathrm{OOH})$ (Movie $\mathrm{S} 1 \dagger$ ) at $\sim 5.37$ ps. The time evolution of key bond distances clearly supports the formation of $(\mathrm{HS}) \mathrm{CH}_{2}(\mathrm{OOH})$. In a recent study, ${ }^{22 b}$ a sizable fraction of the $\mathrm{CH}_{2} \mathrm{OO} \cdots \mathrm{H}_{2} \mathrm{O}$ reactions at the air/water interface has been shown to follow a similar concerted mechanism. The gas-phase calculations suggest that $(\mathrm{HS}) \mathrm{CH}_{2}(\mathrm{OOH})$ is formed with an excess energy of 44.3-44.7 $\mathrm{kcal} \mathrm{mol}^{-1}$. At the air/water interface, this excess energy will be absorbed by the water droplet and the surrounding environment (due to the enforcement of the constant-temperature condition) and (HS) $\mathrm{CH}_{2}(\mathrm{OOH})$ will remain bound to the water surface via hydrogen bonding interaction. Alternatively, (HS) $\mathrm{CH}_{2}(\mathrm{OOH})$ might decompose into HCHS and $\mathrm{H}_{2} \mathrm{O}_{2}$. This reaction is a proton transfer event and might also be mediated by the interfacial water molecules. However, this reaction in the gas-phase involves a barrier of over $49.0 \mathrm{kcal} \mathrm{mol}^{-1}$, and is, thus, unlikely to be observed via BOMD simulations.

In the BOMD simulations, the one $\mathrm{H}_{2} \mathrm{O}$ molecule-mediated concerted $\mathrm{CH}_{2} \mathrm{OO} \cdots \mathrm{H}_{2} \mathrm{~S}$ reaction is the most dominant pathway (Fig. 3 and Movie S2 $\dagger$ ). The reaction involves the formation of a pre-reaction complex involving $\mathrm{CH}_{2} \mathrm{OO}, \mathrm{H}_{2} \mathrm{~S}$ and one $\mathrm{H}_{2} \mathrm{O}$ molecule at 2.73 ps. At this point, the $\mathrm{C}-\mathrm{S}$ bond is $3.0 \AA$ long, and $\mathrm{H}_{2} \mathrm{~S}$ is hydrogen-bonded to $\mathrm{H}_{2} \mathrm{O}\left(\mathrm{O}_{1}-\mathrm{H}_{1}=2.2 \AA\right)$, which, in turn, is hydrogen-bonded to the terminal oxygen of $\mathrm{CH}_{2} \mathrm{OO}\left(\mathrm{O}_{2}-\mathrm{H}_{2}=2.2 \AA\right)$. At $2.77 \mathrm{ps}$, the cyclic $\mathrm{CH}_{2} \mathrm{OO} \cdots \mathrm{H}_{2} \mathrm{~S} \cdots$ 

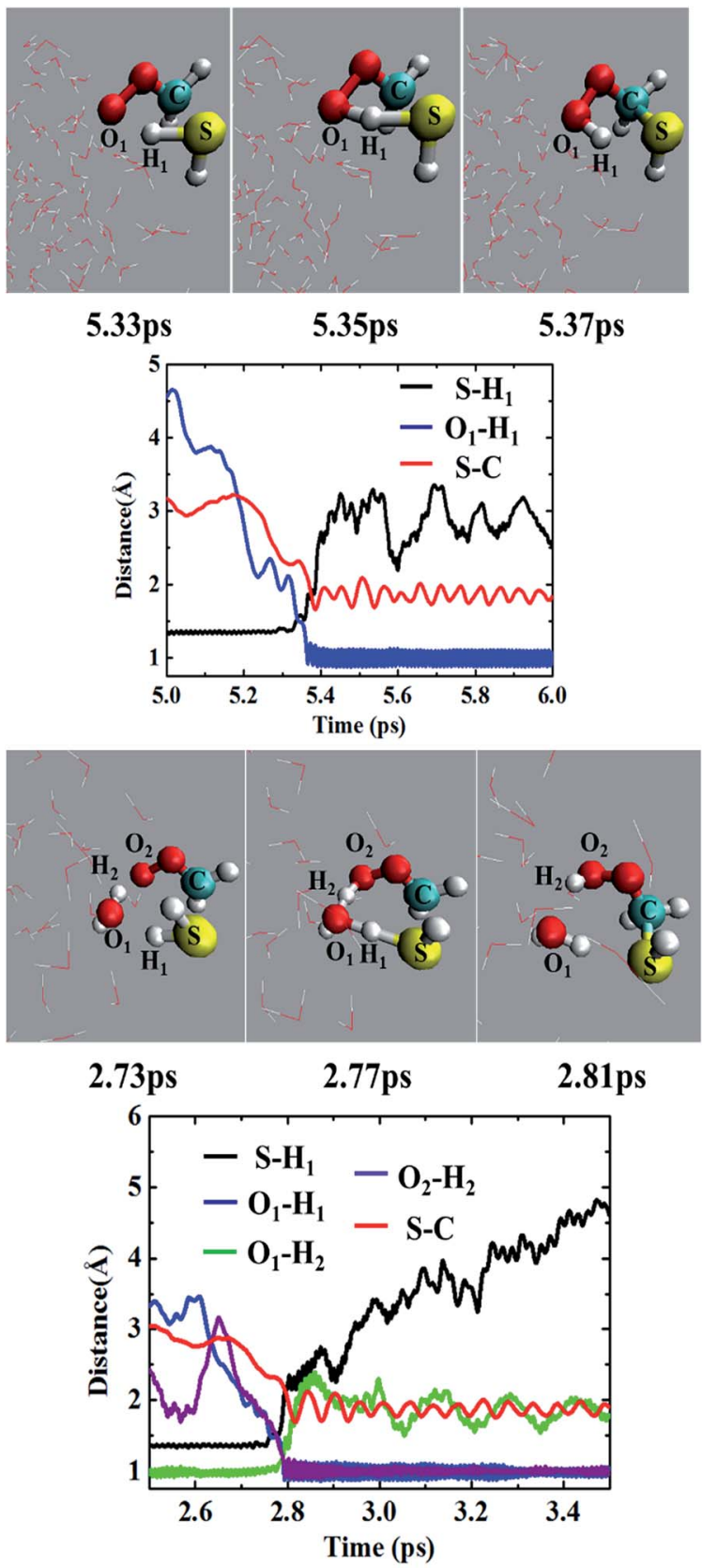

Fig. 3 Top two panels: (upper panel) snapshot structures taken from the BOMD simulation of the reaction between $\mathrm{CH}_{2} \mathrm{OO}$ and $\mathrm{H}_{2} \mathrm{~S}$, which illustrates the concerted formation of the $(\mathrm{HS}) \mathrm{CH}_{2}(\mathrm{OOH})$ without the involvement of any water molecule in the droplet (cloud model), and (lower panel) time evolution of key bond distances, $\mathrm{S}-\mathrm{H}_{1}, \mathrm{C}-\mathrm{S}$ and $\mathrm{O}_{1}-$ $\mathrm{H}_{1}$, in the course of BOMD simulation. Lower two panels: (upper panel) snapshot structures taken from the BOMD simulation for the single water molecule-mediated concerted reaction between $\mathrm{CH}_{2} \mathrm{OO}$ and $\mathrm{H}_{2} \mathrm{~S}$, and (lower panel) time evolution of key bond distances, $\mathrm{S}-\mathrm{H}_{1}, \mathrm{C}-$ $\mathrm{S}, \mathrm{O}_{1}-\mathrm{H}_{1}, \mathrm{O}_{1}-\mathrm{H}_{2}$ and $\mathrm{O}_{2}-\mathrm{H}_{2}$.

$\mathrm{H}_{2} \mathrm{O}$ complex transforms into a transition state like intermediate in which the $\mathrm{S}-\mathrm{C}$ bond is $2.4 \AA$ long, the $\mathrm{S}-\mathrm{H}_{1}$ bond is $1.6 \AA$ long whereas the $\mathrm{O}_{1}-\mathrm{H}_{1}, \mathrm{O}_{1}-\mathrm{H}_{2}$, and $\mathrm{O}_{2}-\mathrm{H}_{2}$ bonds are nearly 1.4 A long. This intermediate immediately converts into the waterbound final product, (HS) $\mathrm{CH}_{2}(\mathrm{OOH}) \cdots \mathrm{H}_{2} \mathrm{O}$ at $2.81 \mathrm{ps}$. The time evolution of key bond distances, S-C, S- $\mathrm{H}_{1}, \mathrm{O}_{1}-\mathrm{H}_{1}, \mathrm{O}_{1}-\mathrm{H}_{2}$, and $\mathrm{O}_{2}-\mathrm{H}_{2}$ corroborate the formation of the postreaction complex in this concerted pathway. The BOMD simulations also suggest the concerted reaction mediated by two $\mathrm{H}_{2} \mathrm{O}$ molecules. The reaction occurs on the ps time scale and is mediated by the prereaction and postreaction complexes, respectively. The formation of the hydrogen-bonded $(\mathrm{HS}) \mathrm{CH}_{2}(\mathrm{OOH})$ in this pathway is also supported by the time evolution profiles of key bond distances (Fig. S1 and Movie S3†).

\section{Stepwise reaction at the air/water interface}

In addition to the concerted mechanism, a noticeable fraction of the $\mathrm{CH}_{2} \mathrm{OO} \cdots \mathrm{H}_{2} \mathrm{~S}$ reaction at the air/water interface $(12.5 \%)$ also proceeds in a stepwise manner. In the first step, the breakage of $\mathrm{H}_{1}-\mathrm{S}$ bond of $\mathrm{H}_{2} \mathrm{~S}$ occurs, leading to the concerted formation of $\mathrm{C}-\mathrm{S}$ bond and $\left(\mathrm{H}_{3} \mathrm{O}\right)^{+}$. This event occurs at $\sim 9.01$ ps. The time evolution profiles of $\mathrm{C}-\mathrm{S}, \mathrm{S}-\mathrm{H}_{1}$ and $\mathrm{O}_{1}-\mathrm{H}_{1}$ bond distances (Fig. 4 and Movie $\mathrm{S} 4 \dagger$ ) clearly show the formation of (HS) $\mathrm{CH}_{2}(\mathrm{OO})^{-}$in the first step. At this point, the $\mathrm{S}-\mathrm{H}_{1}$ bond is elongated to $\sim 2.0 \AA$ whereas the $\mathrm{O}_{1}-\mathrm{H}_{1}$ bond is more like a normal $\mathrm{O}-\mathrm{H}$ bond $(\sim 1.0 \AA)$. These structural changes imply the breakage of $\mathrm{S}-\mathrm{H}_{1}$ bond, and the formation of $\mathrm{C}-\mathrm{S}$ bond and $\left(\mathrm{H}_{3} \mathrm{O}\right)^{+}$, respectively. Notably, there exists no interaction between the terminal Criegee oxygen and hydrogen of nearby $\mathrm{H}_{2} \mathrm{O}$ molecule at this stage $\left(\mathrm{O}_{2}-\mathrm{H}_{2} \sim 1.0 \AA\right)$. In the second step, one water molecule, which is hydrogen-bonded to $\left(\mathrm{H}_{3} \mathrm{O}\right)^{+}$, catalyses the proton $\mathrm{H}_{2}$ transfer from $\left(\mathrm{H}_{3} \mathrm{O}\right)^{+}$to the terminal Criegee oxygen. Following a structural reorganization, a ringlike structure including $\left(\mathrm{H}_{3} \mathrm{O}\right)^{+}$, two $\mathrm{H}_{2} \mathrm{O}$ molecules, and the terminal oxygen of ( $\mathrm{HS}) \mathrm{CH}_{2}(\mathrm{OO})^{-}$is formed at $\sim 9.80 \mathrm{ps}$. This configuration looks like a transition state, showing the two concerted proton transfers, $\left(\mathrm{H}_{3} \mathrm{O}\right)^{+} \rightarrow \mathrm{H}_{2} \mathrm{O} \rightarrow(\mathrm{HS}) \mathrm{CH}_{2}(\mathrm{OO})^{-}$. In this configuration, both the $\mathrm{O}_{1}-\mathrm{H}_{1}$ and $\mathrm{O}_{2}-\mathrm{H}_{2}$ bonds are elongated to $\sim 1.5 \AA$, suggesting the bond formation between the terminal Criegee oxygen and the hydrogen of a nearby water

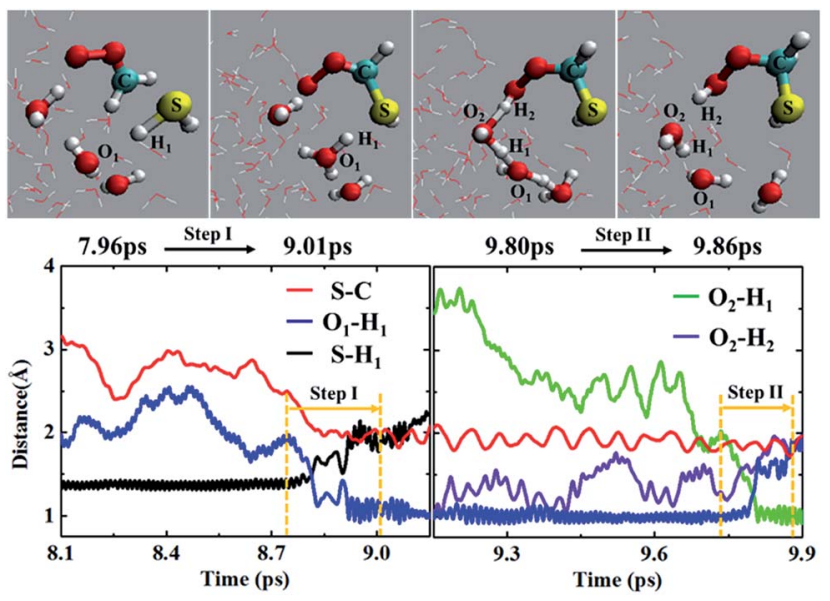

Fig. 4 (Top panel) Snapshot structures taken from the BOMD simulation of the reaction between $\mathrm{CH}_{2} \mathrm{OO}$ and $\mathrm{H}_{2} \mathrm{~S}$, which illustrates the formation of the $(\mathrm{HS}) \mathrm{CH}_{2}(\mathrm{OOH})$ via a stepwise mechanism. (Lower panel) Time evolution of key bond distances, $\mathrm{S}-\mathrm{H}_{1}, \mathrm{~S}-\mathrm{C}, \mathrm{O}_{1}-\mathrm{H}_{1}, \mathrm{O}_{2}-$ $\mathrm{H}_{1}$ and $\mathrm{O}_{2}-\mathrm{H}_{2}$, involved in the stepwise reaction. 
molecule, $\mathrm{H}_{2}$. The formation of ( $\left.\mathrm{HS}\right) \mathrm{CH}_{2}(\mathrm{OOH})$ is complete at $\sim 9.86$ ps. The time insensitivity of $\mathrm{C}-\mathrm{S}$ bond distance beyond 9.0 ps also supports the proton transfer from the water droplet to $(\mathrm{HS}) \mathrm{CH}_{2}(\mathrm{OO})^{-}$in the second step.

Recently, the $\mathrm{CH}_{2} \mathrm{OO} \cdots \mathrm{H}_{2} \mathrm{O}$ reaction at the air/water interface has been found to follow the stepwise mechanism, in addition to the well-known concerted one. ${ }^{22 b}$ It is interesting to compare the stepwise mechanism for the $\mathrm{CH}_{2} \mathrm{OO} \cdots \mathrm{H}_{2} \mathrm{~S}$ reaction with that for the analogous $\mathrm{CH}_{2} \mathrm{OO} \cdots \mathrm{H}_{2} \mathrm{O}$ reaction. The major difference between the two stepwise mechanisms is that for the $\mathrm{CH}_{2} \mathrm{OO} \cdots \mathrm{H}_{2} \mathrm{O}$ reaction, the second step proton transfer from $\left(\mathrm{H}_{3} \mathrm{O}\right)^{+}$to the terminal Criegee oxygen of $(\mathrm{HO}) \mathrm{CH}_{2}(\mathrm{OO})^{-}$occurs without the involvement of any additional $\mathrm{H}_{2} \mathrm{O}$ molecule, whereas for the $\mathrm{CH}_{2} \mathrm{OO} \cdots \mathrm{H}_{2} \mathrm{~S}$ reaction, the proton transfer from $\left(\mathrm{H}_{3} \mathrm{O}\right)^{+}$to the (HS) $\mathrm{CH}_{2}(\mathrm{OO})^{-}$is catalyzed by a $\mathrm{H}_{2} \mathrm{O}$ molecule.

The above analysis shows that the air/water interface can mediate the $\mathrm{CH}_{2} \mathrm{OO} \cdots \mathrm{H}_{2} \mathrm{~S}$ reaction. To fully understand the role of water droplet, the hydration structure, orientation and dynamical behaviour of $\mathrm{CH}_{2} \mathrm{OO}$ and $\mathrm{H}_{2} \mathrm{~S}$ on the water droplet is analysed next.

\section{Effects of water droplet}

Fig. 5 shows three typical orientations (I, II, and III) of $\mathrm{H}_{2} \mathrm{~S}$ on the water droplet and their corresponding probabilities. The orientation II has the highest probability, indicating the $\mathrm{H}$ atom of $\mathrm{H}_{2} \mathrm{~S}$ prefers to interact with the water droplet due to hydrogen bonding $\mathrm{H}\left(\mathrm{H}_{2} \mathrm{~S}\right) \cdots \mathrm{O}\left(\mathrm{H}_{2} \mathrm{O}\right)$ interaction. See Fig. $\mathrm{S} 2 \uparrow$ for the radial distribution function. Closer inspection of orientation II shows that only one of the two $\mathrm{H}$ atoms in $\mathrm{H}_{2} \mathrm{~S}$ forms hydrogen bond with the water droplet (see Fig. S3 $\dagger$ ). This allows $\mathrm{H}_{2} \mathrm{~S}$ to transfer one of its $\mathrm{H}$ atoms to $\mathrm{H}_{2} \mathrm{O}$ molecules easily, which, in turn, favours the $\mathrm{CH}_{2} \mathrm{OO} \cdots \mathrm{H}_{2} \mathrm{~S}$ reaction. Similarly, the orientation III, where one $\mathrm{H}$ atom in $\mathrm{H}_{2} \mathrm{~S}$ interacts with water, would favour the proton transfer from $\mathrm{H}_{2} \mathrm{~S}$ to the water droplet.

Next, the hydration of $\mathrm{CH}_{2} \mathrm{OO}$ on the surface of the water droplet is investigated by computing the joint probability distributions $\left(P\left(\theta_{\mu}, \varphi\right)\right)$ for $\mathrm{H}_{2} \mathrm{O}$ molecules within the first hydration shell of $\mathrm{CH}_{2} \mathrm{OO}$ (Fig. 6). $P\left(\theta_{\mu}, \varphi\right)$ is uniquely defined by two angular coordinates, $\theta_{\mu}$ and $\varphi$. The $\theta_{\mu}$ is the angle formed by the vector between the $\mathrm{H}_{2} \mathrm{O}$ oxygen and the specified atoms $\overrightarrow{r_{\text {os }}}$, and the

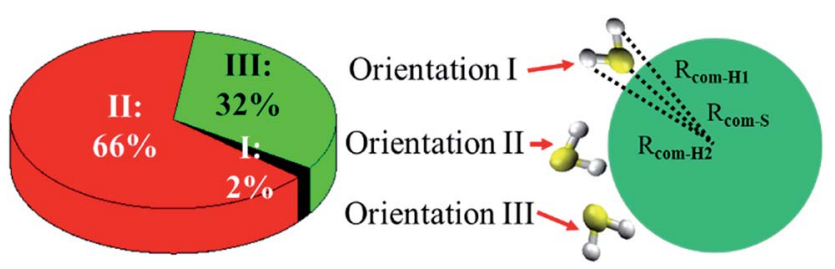

Fig. 5 Orientations (I, II, and III) of $\mathrm{H}_{2} \mathrm{~S}$ at the air/water interface and their probabilities. Orientation I corresponds to $R_{\mathrm{com}-\mathrm{S}}<R_{\mathrm{com}-\mathrm{H} 1}<$ $R_{\mathrm{com}-\mathrm{H} 2}$. Orientation II corresponds to $R_{\mathrm{com}-\mathrm{H} 1}<R_{\mathrm{com}-\mathrm{H} 2}<R_{\mathrm{com}-\mathrm{S}}$ Orientation III corresponds to $R_{\mathrm{com}-\mathrm{H} 1}<R_{\mathrm{com}-\mathrm{S}}<R_{\mathrm{com}-\mathrm{H} 2}$. $R_{\mathrm{com}-\mathrm{H} 1}$, $R_{\text {com-H2 }}$ and $R_{\text {com-s }}$ represent the distance between $\mathrm{S}\left(\mathrm{H}_{2} \mathrm{~S}\right), \mathrm{H} 1\left(\mathrm{H}_{2} \mathrm{~S}\right)$, and $\mathrm{H}_{2}\left(\mathrm{H}_{2} \mathrm{~S}\right)$ and center of mass (COM) of the water droplet. $\mathrm{H} 1$ is the hydrogen atom in $\mathrm{H}_{2} \mathrm{~S}$ with shorter distance from the COM of the water droplet.
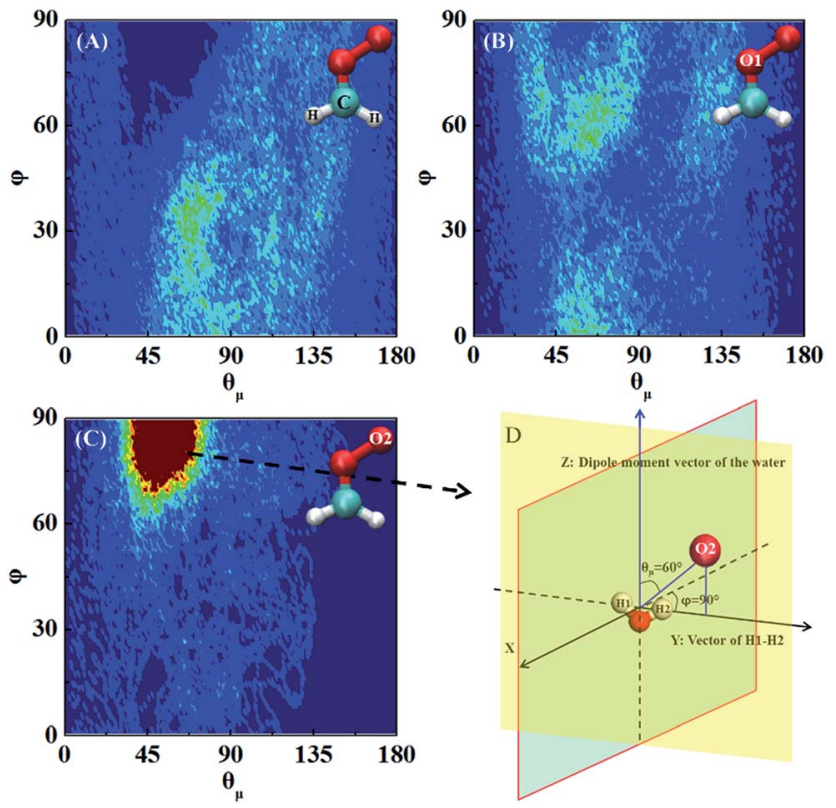

Fig. 6 Joint probability distributions $P\left(\theta_{\mu}, \varphi\right)$ computed for water molecules within the first hydration shell of the $\mathrm{CH}_{2} \mathrm{OO}$ at air/water interface; (A) $-\mathrm{CH}_{2}$ (B) $\mathrm{O} 1$ (C) O2. Red and blue colours represent high and low probabilities, respectively. The high probability orientation between $\mathrm{CH}_{2} \mathrm{OO}$ and $\mathrm{H}_{2} \mathrm{O}$ is shown in (D).

dipole moment vector of the $\mathrm{H}_{2} \mathrm{O}$ molecule $\vec{\mu}$, where $\vec{r}$ os points to the direction of the specified atoms. The coordinate $\varphi$ is the angle made by the projection of $\vec{r}$ os onto a local $X Y$-plane and the local $X$-axis, which is normal to the $\mathrm{H}-\mathrm{O}-\mathrm{H}$ plane. Based on the computed $P\left(\theta_{\mu}, \varphi\right)$, it can be seen that there is no obvious strong interaction between the water droplet and either $-\mathrm{CH}_{2}$ or $\mathrm{O} 1$ of $\mathrm{CH}_{2} \mathrm{OO}$. However, the $\mathrm{O}_{2}$ atom of $\mathrm{CH}_{2} \mathrm{OO}$ interacts strongly with a nearby $\mathrm{H}_{2} \mathrm{O}$ molecule (Fig. 6C). See also Fig. $\mathrm{S} 4 \uparrow$ for the radial distribution function. In the high probability region (Fig. 6D), the $\varphi$ is around $90^{\circ}$ and $\theta_{\mu}$ is close to $60^{\circ}$, which is indicative of the fact that there exists a strong hydrogen bond, $\mathrm{O} 2\left(\mathrm{CH}_{2} \mathrm{OO}\right) \cdots \mathrm{H}\left(\mathrm{H}_{2} \mathrm{O}\right)$, and the $\mathrm{H}$ atoms of nearby $\mathrm{H}_{2} \mathrm{O}$ in the droplet are easily transferrable to $\mathrm{CH}_{2} \mathrm{OO}$.

\section{“Trapping" effects of the water droplet}

Why does the concerted $\mathrm{CH}_{2} \mathrm{OO}-\mathrm{H}_{2} \mathrm{~S}$ reaction without the direct involvement of nearby water molecules on the water droplet occur on a ps time scale? According to the hydration structure analysis, the $\mathrm{H}$ atom of $\mathrm{H}_{2} \mathrm{~S}$ and $\mathrm{O}_{2}$ atom of $\mathrm{CH}_{2} \mathrm{OO}$ prefer to interact with $\mathrm{H}_{2} \mathrm{O}$ near the surface of the droplet whereas, the $\mathrm{S}$ atom of $\mathrm{H}_{2} \mathrm{~S}$ and $\mathrm{C}$ atom of $\mathrm{CH}_{2} \mathrm{OO}$ exhibit relatively weak interaction with the water droplet, and both are located at a further distance from the droplet, which implies the possibility of $\mathrm{C}-\mathrm{S}$ bond forming reaction. The $\mathrm{H}_{2} \mathrm{O}$ molecules in the droplet can make the configurations of $\mathrm{H}_{2} \mathrm{~S}$ and $\mathrm{CH}_{2} \mathrm{OO}$ favourable to form pre-reaction complex, and stabilize such configurations due to trapping effect, thereby allowing the concerted reaction to occur within ps. 


\section{Conclusions}

In summary, we have shown evidence from the Born-Oppenheimer molecular dynamics simulations that at the air/water interface, a significant fraction of Criegee intermediate, $\mathrm{CH}_{2} \mathrm{OO}(50 \%)$ reacts with $\mathrm{H}_{2} \mathrm{~S}$. Importantly, the reaction of $\mathrm{CH}_{2} \mathrm{OO}$ with $\mathrm{H}_{2} \mathrm{~S}$ at the air/water surface occurs on a picosecond time scale and follows both concerted and stepwise mechanisms with former being the dominant pathway. The concerted reaction between $\mathrm{CH}_{2} \mathrm{OO}$ and $\mathrm{H}_{2} \mathrm{~S}$ mediated by one and two water molecules on the water droplet are two of the most dominant pathways. An important mechanistic difference between the $\mathrm{CH}_{2} \mathrm{OO} \cdots \mathrm{H}_{2} \mathrm{~S}$ and $\mathrm{CH}_{2} \mathrm{OO} \cdots \mathrm{H}_{2} \mathrm{O}$ reactions is that the proton transfer in the stepwise $\mathrm{H}_{2} \mathrm{~S}$ reaction is mediated by a water molecule, whereas the proton transfer in the stepwise $\mathrm{H}_{2} \mathrm{O}$ reaction occurs without the involvement of any additional water molecule. To our knowledge, this is the first simulation evidence of $\mathrm{C}-\mathrm{S}$ bond formation via Criegee $\cdots \mathrm{H}_{2} \mathrm{~S}$ reaction at the air/water interface. This new Criegee $\cdots \mathrm{H}_{2} \mathrm{~S}$ chemistry could be a new oxidation pathway for $\mathrm{H}_{2} \mathrm{~S}$ in terrestrial, geothermal and volcanic regions.

\section{Acknowledgements}

This work is supported by the National Science Foundation (CHE-1500217), and a fund from Beijing Advanced Innovation Center for Soft Matter Science \& Engineering for summer visiting scholar, and by the University of Nebraska Holland Computing Center.

\section{References}

1 (a) N. J. Evans, C. H. Townes, H. F. Weaver and D. R. Williams, Science, 1970, 169, 680; (b) M. W. Sinclair, N. Fourikis, J. C. Ribes, B. J. Robinson, R. D. Brown and P. D. Godfrey, Aust. J. Phys., 1973, 26, 85; (c) Y. C. Minh, W. M. Irvine and M. K. Brewer, Astron. Astrophys., 1991, 244, 181.

2 M. Agundez, J. P. Fonfria, J. Cernicharo, J. R. Pardo and M. Guelin, Astron. Astrophys., 2008, 479, 493.

3 R. Okazaki, in Organosulfur Chemistry, ed. P. D. Page, Academic Press, London, 1995, p. 226.

4 E. Vedejs, D. A. Perry, K. N. Houk and N. G. Rondan, J. Am. Chem. Soc., 1983, 105, 6999.

5 W. M. McGregor and D. C. Sherrington, Chem. Soc. Rev., 1993, 22, 199.

6 K. D. Allen, D. V. Miller, B. J. Rauch, J. J. Perona and R. H. White, Biochemistry, 2015, 54, 3129.

7 M. Kumar and J. S. Francisco, Chem.-Eur. J., 2016, 22, 1. 8 R. H. Judge and G. W. King, Can. J. Phys., 1975, 53, 1927.

9 M. Kumar and J. S. Francisco, Angew. Chem., Int. Ed., 2016, 55, 13432-13435.

10 R. Criegee, Angew. Chem., Int. Ed., 1975, 14, 745.

11 (a) O. Welz, J. D. Savee, D. L. Osborn, S. S. Vasu, C. J. Percival, D. E. Shallcross and C. A. Taatjes, Science, 2012, 335, 204; (b) C. A. Taatjes, O. Welz, A. J. Eskola, J. D. Savee, A. M. Scheer,
D. E. Shallcross, B. Rotavera, E. P. F. Lee, J. M. Dyke, D. K. W. Mok, et al., Science, 2013, 340, 177.

12 D. L. Osborn and C. A. Taatjes, Int. Rev. Phys. Chem., 2015, 34, 309-360.

13 H. Leisch, K. Morley and P. Lau, Chem. Rev., 2011, 111, 4165. 14 S. G. Van Ornum, R. M. Champeau and R. Pariza, Chem. Rev., 2006, 106, 2990.

15 US EPA, 1993 Report to Congress on hydrogen sulfide air emis- sions associated with the extraction of oil and natural gas. Research Triangle Park, NC, US Environmental Protection Agency, Office of Air Quality Planning and Standards EPA/453/R93045; NTIS Publication No. PB941312240.

16 P. Brimblecombe, Air Composition and Chemistry, Cambridge University Presss, 1996.

17 J. Bogner and D. Heguy, Msw Management, March-April 2004. 18 S. Lee, Q. Xu, M. Booth, T. G. Townsend, P. Chadik and G. Bitton, Waste Manag., 2006, 26, 526-533.

19 B. K. Takemoto, R. D. Noble and H. M. Harrington, New Phytol., 1986, 103, 541.

20 F. B. Hill, Brookhaven Symp. Biol., 1973, 30, 159.

21 L. Vereecken, D. R. Glowacki and M. J. Pilling, Chem. Rev., 2015, 115, 4063.

22 (a) A. R. Ravishankara, Science, 1997, 276, 1058; (b) C. Q. Zhu, M. Kumar, J. Zhong, L. Lei, J. S. Francisco and X. C. Zeng, J. Am. Chem. Soc., 2016, 138, 11164; (c) L. Li, M. Kumar, C. Q. Zhu, J. Zhong, J. S. Francisco and X. C. Zeng, J. Am. Chem. Soc., 2016, 138, 1816; (d) J. Zhong, Y. Zhao, L. Li, H. Li, J. S. Francisco and X. C. Zeng, J. Am. Chem. Soc., 2015, 137, 12070.

23 (a) I. Gultepe and G. A. Isaac, Q. J. R. Meteorol. Soc., 2004, 130, 2377; (b) P. Guyon, B. Graham, J. Beck, O. Boucher, E. Gerasopoulos, O. L. Mayol-Bracero, G. C. Roberts, P. Artaxo and M. O. Andreae, Atmos. Chem. Phys., 2003, 3, 951.

24 F. Pouliquen, C. Blanc and E. Arretz, et al., Hydrogen sulfide, in Ullmann's encyclopedia of industrial chemistry, highperformance fibers to imidazole and derivatives, ed. B. Elvers, S. Hawkins and M. Revenscroft, VCH Publishers, Deerfield, Beach, FL, 1989, vol. A13, pp. 467-485.

25 J. VandeVondele, M. Krack, F. Mohamed, M. Parrinello, T. Chassaing and J. Hutter, Comput. Phys. Commun., 2005, 167, 103.

26 (a) A. D. Becke, Phys. Rev. A: At., Mol., Opt. Phys., 1988, 38, 3098; (b) C. T. Lee, W. T. Yang and R. G. Parr, Phys. Rev. B: Condens. Matter Mater. Phys., 1988, 37, 785.

27 S. Grimme, J. Antony, S. Ehrlich and H. Krieg, J. Chem. Phys., 2010, 132.

28 J. VandeVondele and J. Hutter, J. Chem. Phys., 2007, 127.

29 (a) C. Hartwigsen, S. Goedecker and J. Hutter, Phys. Rev. B: Condens. Matter Mater. Phys., 1998, 58, 3641; (b) S. Goedecker, M. Teter and J. Hutter, Phys. Rev. B: Condens. Matter Mater. Phys., 1996, 54, 1703.

30 R. A. Kendall, T. H. Dunning Jr and R. J. Harrison, J. Chem. Phys., 1992, 96, 6796.

31 J. Noga and R. J. Bartlett, J. Chem. Phys., 1987, 86, 7041. 
32 M. J. Frisch, G. W. Trucks, H. B. Schlegel, G. E. Scuseria, M. A. Robb, J. R. Cheeseman, G. Scalmani, V. Barone, B. Mennucci, G. A. Petersson, et al., Gaussian 09, Revision D.01, Gaussian, Inc., Wallingford CT, 2009.

33 J. Kalinowski, M. Rasanen, P. Heinonen, I. Kilpelainen and R. B. Gerber, Angew. Chem., Int. Ed., 2014, 53, 265-268.

34 J. M. Anglada, J. Gonzalez and M. Torrent-Sucarrat, Phys. Chem. Chem. Phys., 2011, 13, 13034-13045.
35 F. Liu, Y. Fang, M. Kumar, W. H. Thompson and M. I. Lester, Phys. Chem. Chem. Phys., 2015, 17, 20490-20494.

36 M. Kumar, D. H. Busch, B. Subramaniam and W. H. Thompson, Phys. Chem. Chem. Phys., 2014, 16, 22968-22973.

37 J. Zhong, M. Kumar, C. Q. Zhu, J. S. Francisco and X. C. Zeng, Angew. Chem., Int. Ed., 2017, 56, DOI: 10.1002/anie.201702722. 